\title{
PENSANDO O SUICÍDIO SOB A ÓTICA FENOMENOLÓGICA HERMENÊUTICA: ALGUMAS CONSIDERAÇÕES
}

\author{
Thinking About Suicide under the Phenomenolocial Hermeneutics: Some Considerations \\ Pensal el Suicidio en la Hermenéutica Fenomenológica: Algunas Consideraciones
}

Elza Dutra

\begin{abstract}
Resumo: Este trabalho tem como objetivo desenvolver algumas reflexões sobre o suicídio a partir da perspectiva fenomenológicahermenêutica heideggeriana. As noções heideggerianas de ser-aí, ser-no-mundo, angústia e ser-para-morte nortearão as reflexões aqui iniciadas. Para isso utilizamos as narrativas de seis adolescentes que tentaram suicídio, apresentadas em nossa pesquisa de doutorado. Pretende-se, a partir da experiência desses jovens, alcançar uma compreensão mais profunda do suicídio, uma vez que as considerações terão como horizonte a concretude da experiência vivida. Entendendo o ser-aí, o Dasein, como um ser de abertura e, portanto, de possibilidades, a morte se apresenta como a última possibilidade existencial. Na realidade, a morte representa a possibilidade mais concreta com a qual o homem pode contar, como propõe Martin Heidegger. A morte afirma a finitude da vida e da existência. Sobretudo, representa a única certeza para o ser humano. Nesse sentido, interrogamos se o suicídio poderia ser pensado como a falta de sentido de si mesmo e um modo impessoal de se lidar com a angústia, eliminando-a. Significaria o desespero por não suportar a finitude da existência? Os questionamentos representam um esforço no sentido de pensar o suicídio a partir de um olhar que contemple a dimensão existencial que caracteriza o Dasein em sua busca de sentido como ser-no-mundo. Esperamos, assim, contribuir para a construção de um olhar desprovido de rótulos e categorizações, como histórica e cientificamente o suicídio tem sido abordado.
\end{abstract}

Palavras-chave: Suicídio; Fenomenologia hermenêutica; Ser-para-morte; Heidegger.

\begin{abstract}
This work aims to develop some thoughts about suicide from the perspective of phenomenological-hermeneutics. The Heideggerian notions of being there, being in the world, anguish and death-to-be will guide the discussions started here. For that use the stories of six teenagers who attempted suicide, presented in our doctoral research. We intend, from the experience of these young people, achieve a deeper understanding of suicide, since the horizon considerations will have the concreteness of lived experience. Understanding the being-there, Dasein, as being an opening and, therefore, opportunities, death is presented as the ultimate existential possibility. In fact, death represents the most concrete possibility with which the man can count, as proposed by Heidegger. Death claims the finitude of life and existence. Above all, the only certainty is that you have in life. In this sense, we question whether the suicide could be thought of as a lack of sense of self and an impersonal way of dealing with anxiety, eliminating it. Despair would not support the finitude of existence? The questions represent an effort to think of suicide from a look that encompasses the existential dimension that characterizes Dasein in its search for meaning as being in the world. We hope thus to contribute to building a look devoid of labels and categorizations, as historically and scientifically suicide has been discussed.
\end{abstract}

Keywords: Suicide; Hermeneutic phenomenology; Being-for-death; Heidegger.

Resumen: Este trabajo tiene como objetivo desarrollar algunas reflexiones sobre el suicidio desde la perspectiva de la hermenéutica fenomenológica-. Las nociones de Heidegger de estar ahí, estar en el mundo, la angustia y la muerte-a-ser guiará las discusiones iniciadas aquí. Para obtener que el uso de la historia de seis adolescentes que intentaron suicidarse, se presentan en nuestra investigación doctoral. Se pretende, a partir de la experiencia de estos jóvenes, lograr una comprensión más profunda de suicidio, ya que las consideraciones tendrá en el horizonte la concreción de la experiencia vivida. La comprensión del ser-ahí, Dasein, como una apertura y, por tanto, las oportunidades, la muerte se presenta como la posibilidad existencial final. De hecho, la muerte representa la posibilidad más concreta con la que el hombre puede contar, según lo propuesto por Heidegger. La muerte reclama la finitud de la vida y la existencia. Por encima de todo, es la única certeza que el ser humano tiene en la vida. En este sentido, nos preguntamos si el suicidio podría ser considerado como una falta de sentido del yo y de una manera impersonal de tratar con la ansiedad, eliminando la misma. La desesperación no apoyaría la finitud de la existencia? Las preguntas representan un esfuerzo para pensar en el suicidio de una mirada que abarca la dimensión existencial que caracteriza el Dasein en su búsqueda de un sentido como ser en el mundo. Esperamos contribuir así a la construcción de una mirada desprovista de etiquetas y categorías, como histórica y científicamente, el suicidio se ha discutido.

Palabras-clave: Suicidio; Fenomenología hermenéutica; Ser-para-la muerte; Heidegger. 


\section{Introdução}

O objetivo deste artigo é refletir acerca do suicídio sob a ótica fenomenológico- existencial, a partir de pesquisa realizada com adolescentes que tentaram suicídio (Dutra, 2000). Embora se saiba que as tentativas de suicídio (TS) diferem do suicídio (S) em relação a algumas características, tais como: população - os homens cometem mais suicídio e as mulheres, mais tentativas; faixa etária e meio causador - quando relacionados ao gênero e contexto cultural, são diferentes no S e na TS, consideramos que refletir sobre o suicídio a partir de depoimentos de quem tentou se matar nos aproxima desse fenômeno (Dutra, 2002; 2010). Não nos propomos a dar respostas sobre o suicídio, uma vez que o único consenso existente entre os suicidologistas é o de que esse ato é multideterminado, acontecendo quando um conjunto de fatores ambientais une-se a determinados modos de ser. Não é possível, portanto, traçar um perfil do suicida, como sugerem alguns mitos construídos em torno desse fenômeno.

O motivo ou motivos que levam alguém ao suicídio formam-se ao longo da sua história e se revelam nos sentidos e modos de ser que constituem a sua existência. Por isso esse fenômeno não escolhe idade, classe social, gênero ou nacionalidade. Em nosso entendimento, o suicídio significa, antes de tudo, sofrimento e desespero; ou, como disse Camus (1952), consiste mais numa questão filosófica, uma vez que interroga sobre o sentido da vida. Assim, o nosso intuito é iniciar uma reflexão que, nesse momento, se anuncia como um esboço de idéias e questionamentos de natureza fenomenológica e existencial sobre o tema tratado.

Tendo como horizonte a reflexão pretendida, adotamos como ponto de partida para este trabalho as entrevistas realizadas com seis jovens que tentaram suicídio (cinco mulheres e um homem), com idades entre 15 e 20 anos, participantes de um estudo de doutoramento (Dutra, 2000) ${ }^{1}$. Sendo assim, as reflexões empreendidas, aqui, sobre o suicídio, em alguns momentos envolvem as TS, uma vez que o desejo de interromper a vida, presente em ambas as situações, nos permite pensar o suicídio numa dimensão existencial e vivenciada através da narrativa de quem esteve próximo da experiência do suicídio. As idéias aqui esboçadas terão como referência teórica e filosófica a fenomenologia existencial segundo o pensamento do filósofo alemão Martin Heidegger.

Não causa estranheza se constatar a busca incessante do ser humano pela explicação do seu viver, e do morrer também. De onde viemos e para onde vamos, é a interrogação que atravessa a existência. Por isso, a finitude é uma das questões mais significativas e presentes nas corren-

\footnotetext{
A referida pesquisa foi desenvolvida no Programa de Doutorado em Psicologia Clínica da Universidade de São Paulo (USP). A pesquisa teve aprovação do Comitê de Ética em Pesquisa e cumpriu todos os requisitos exigidos para a sua realização.
}

tes existencialistas. Talvez seja esta a razão da busca dos motivos e a explicação para o desejo de não mais viver, observado de maneira tão clara nas narrativas dos adolescentes sobre as suas experiências ao tentar o suicídio. Percebe-se, em todas elas, uma fala que aponta os motivos de cada um, as situações e pessoas envolvidas na experiência. A experiência narrada é sempre relacionada a momentos de vida e fatos que conduziram o jovem àquele ato de desespero. Há sempre um motivo ou motivos que são apontados como geradores da crise e que sinalizam para o suicídio como uma saída para o sofrimento.

As experiências de vida desses jovens revelam que a maioria deles encontra-se mergulhada em famílias desestruturadas emocionalmente, com histórias de agressões físicas e abusos sexuais, geralmente ocorridas no seio da própria família. As narrativas revelam experiências de vida comumente marcadas pela rejeição, abandono e incompreensão. Os motivos causadores da tentativa de suicídio sempre são identificados pelos participantes da pesquisa. Há um sentido, na forma de uma razão aparente e consciente que explica o ato que cada um cometeu contra si mesmo, demonstrando uma compreensibilidade dos motivos de cada um, o que pode ser entendido como a presença da compreensão, uma das estruturas existenciárias da Analítica Existencial, proposta por Heidegger (1927/1999). As falas de Leila e Marta (todos os participantes do estudo que aqui serão citados receberam nomes fictícios) ilustram essa compreensão:

Leila:...eu acho que a tentativa de suicídio é mais o "rejeitamento"... Eu acho que pra pessoa tentar se suicidar sempre tem que ter um motivo. A pessoa não vai tentar querer tirar a vida sem ter um motivo... tem aquele motivo... do problema....

Senti vontade de morrer por causa de um homem sem futuro.... Um rapaz sem futuro... que não presta.... Eu pensei em morrer por causa dele....

Marta: Esses pensamentos passam pela minha cabeça,.quando eu penso em resolver todos os problemas... Aí eu digo: "Eu vou fazer isso... vou resolver tudo..." mas eu acho que não....Queria resolver os problemas... Não quero brigar com meu irmão... Eu tinha que segurar a barra antigamente. Me dava raiva... Aí eu não aguentava...

Nessas falas, os motivos alegados sempre se localizam na figura de um outro, representado pela família, namorado, marido e situações desfavoráveis de vida, enfim, pelo outros entes do mundo, trazendo à tona o caráter de mundanidade do Dasein. Podemos perceber a presença da cotidianidade na qual esses jovens estão mergulhados, na ruína e decadência, pela absorção de um outro que não é o seu ser, revelando-se como um modo-de-ser na impessoalidade cotidiana. Nesse contexto, percebe-se o momento em que a crise se instala. Nesse sentido lembramos Procópio (1999), ao dizer que a crise que surge 
na convivência com um desses outros concretos serve para deixar à mostra e revelar uma angústia que já está aí, porque é originária do ser, como nos faz ver Heidegger (1927/1999). Angústia que ao ser desvelada, e diante da dor que provoca, faz surgir a necessidade de nomeá-la, de fazê-la compreensível, a fim de aliviar o desespero de não se saber. E o que acontece a seguir, é o que geralmente se observa acontecer em um momento como esse. Não raro se aponta um motivo, um acontecimento ou se atribui ao outro a razão do ato, além de este outro ser considerado o elemento causador e responsável pelo acontecimento. Na verdade, é a angústia que não é encarada, e da qual o Dasein não se apropria, como parte da sua existência. É a revelação do ser e também do não ser. Porque é nessa dimensão de velamento e desvelamento que se dá a pre-sença, ou seja, a existência. Pois como diz Novaes de Sá (2010):

O Dasein foge de si, esquecendo-se do seu "ser próprio”, relacionando-se com ele como algo que já tem uma configuração preestabelecida. A ausência de surpresas e a evidência caracterizam a ocupação e a preocupação cotidianas. O modo de falar e escrever descomprometido (falatório e escritório), a forma despersonalizada e insaciável de lidar com o novo para preservar o conhecido, evitando as transformações (curiosidade), constituem o modo de ser cotidiano do Dasein (p. 185).

No entanto, é justamente no momento da crise que a angústia pode ser facilitadora de uma mudança nos sentidos da existência. Como disse Heidegger (1927/1999), nessa situação duas possibilidades se colocam diante do ser: continuar na ruína, ou seja, absorvido pela cotidianidade e permanecer na impessoalidade ou se apropriar do si mesmo, ao buscar uma existência mais autêntica. A respeito da angústia, Novaes de Sá (2010, p. 188) diz:

Referimo-nos, anteriormente, à angústia como a disposição que leva à possibilidade de singularização, por colocar o Dasein em contato com o seu ser mais próprio, que é a existência como abertura de sentido. Sendo o ser-para-a-morte a possibilidade mais própria, irremissível e insuperável do homem como projeto, pode-se dizer que toda angústia aponta, em última instância, para o caráter temporal e finito da existência.

Como se pode ver nos atos de suicídio, a escolha tem sido a morte, ou seja, a eliminação da angústia na vivência da última possibilidade do Dasein, a morte. Quando não se abre à angústia, parte-se para localizar no mundo concreto, no outro, e não em si mesmo, uma explicação para a dor. O mundo é responsável pela angústia vivida. É preciso conhecer, classificar e catalogar o sofrimento. Este, decorrente da angústia, necessita ser nomeado e compreendido. É difícil para o homem olhar de frente a sua finitude, porque ao fazê-lo, além de enfrentar a certeza da morte, toma consciência de que ninguém jamais poderá viver por ele, desvelando-se, assim, o seu poder-ser; portanto, é preciso se apropriar da vida e das suas escolhas. A possibilidade da morte revela a vida que se vive. E enfrentar a realidade da vida que se tem muitas vezes é tão frustrante, que em muitas pessoas prevalece a intolerância à dor, conduzindo-os, freqüentemente, a escolher a morte $\mathrm{e}$ assim, escapar do sofrimento. $\mathrm{O}$ sofrimento de empunhar o seu si mesmo, de apropriar-se da sua existência assumindo todas as implicações que dela decorrem.

A morte, enquanto uma possibilidade, é presente no ser-aí, constituindo-se, portanto, numa abertura que vai ao encontro do Dasein. Entretanto, no mundo contemporâneo em que vivemos, numa sociedade líquida, como pensa Bauman (2007), o que se percebe é uma busca incessante e a qualquer preço, da felicidade. E para isso elimina-se qualquer sofrimento; todo mal-estar será banido, "tratado" e curado, criando-se, inclusive, uma cultura de medicalização, como a que vivemos atualmente, e que tem sido objeto de estudos, como os de Dantas (2009). Nesse contexto, a condição de sofrente que somos não tem lugar nesse mundo, como não há espaço para se ser triste, frágil, ou simplesmente ser diferente do modo de ser proposto pela sociedade capitalista e de consumo que prevalece no mundo globalizado. Assim, o mundo torna-se cada vez mais inóspito para o ser humano, que se desenraíza e perde, lentamente, a sua morada, o seu ethos (Figueiredo, 1996; Safra, 2004; Dutra 2004).

Nesse contexto de mundo, a ansiedade ocupa o vácuo deixado pelo não-ser. A existência, quando vivida na impessoalidade, leva o Dasein, cada vez mais, a afastar-se dos sentidos que lhes são próprios, e desse modo, perder a sua singularidade. Tal modo de viver pode gerar ansiedade e muitas vezes, depressão; esses modos de ser nada mais representam do que um não-ser, ou seja, a perda de sentido. Quando essas disposições afetivas levam o sofrente aos seus limites mais extremos e o desespero torna-se insuportável, então a possibilidade da morte passa a representar o sentido para eliminar tal sofrimento.

Para os jovens do estudo referenciado neste artigo, a tarefa de ser autêntico, de se apropriar de si mesmo torna-se mais difícil ainda ou mesmo impossibilitada de ocorrer, quando se considera as diversas circunstâncias que envolvem as suas existências. Além de jovens em plena adolescência, momento esse marcado pelos conflitos próprios da fase em que se encontram, eles ainda têm que lidar, e como se vê, de forma dolorosa, com as vicissitudes da sua existência concreta, seja no âmbito familiar, seja no contexto social mais amplo. As famílias do estudo referenciado, em sua maioria, eram famílias desestruturadas; os pais não favoreciam vínculos afetivos positivos com os seus filhos, quando os assumiam; quando não, atiravam-nos ao mundo para que eles enfrentassem as suas mudanças e adversidades por conta própria. Ou seja, os pais, como se percebe nos depoimentos, 
não possuíam recursos, em todos os sentidos que a palavra evoca, para lidar com a problemática dos seus filhos e exercer um cuidado de um modo pré-ocupado, como pensa (Heidegger, 1927/1999). As palavras de Leila são um exemplo da condição de abandono e desamparo em que essas meninas muitas vezes se encontram. A morte, então, surge como uma maneira de se defender do outro, revelando um desespero e uma busca de proteção. Nessas condições, a morte parece ser uma saída:

Leila: Depois....por conta de um namorado...infernizaram a minha vida.... começaram a me agredir...a dizer coisas comigo...minhas tias me chamando de rapariga... me chamando de um monte de coisa... aí eu não tinha como... não sabia como me defender. A única maneira que eu achei de me defender foi ou me matar... ou então dizer que não me lembrava de nada. Aí eu tentei me suicidar....

Não são raras a utilização de drogas, tanto as lícitas, como as bebidas alcoólicas, quanto as ilícitas, além do envolvimento de alguns jovens com traficantes. As experiências de algumas adolescentes também falam de depressão, internamentos em hospitais psiquiátricos, como mostram os depoimentos de Elizabete e Leila.

Elizabete: Sinceramente... eu não estou entendendo o que se passa comigo. Estou num estágio de vida em que me vejo parada... eu estacionei Eu nem ando... nem volto... nem para um lado e nem para o outro.... Eu parei.... E tenho tido crises depressivas.... Às vezes eu páro em casa e fico pensando em quantas vezes eu quis me matar. Por que será...?

Leila: E depois disseram que eu estava doida e então me internaram na Casa de Saúde. Depois de muito tempo... quando aconteceram esses problemas com o meu namorado... eu fui pra lá. Antes disso eu saí de casa.... Cheguei quase a tomar um litro de cachaça.... Não tomei porque não deixaram... Isso foi há quatro anos atrás ou mais ou menos cinco anos atrás.... Eu tinha em torno de doze anos.... Depois disso... me internaram no hospital psiquiátrico.

A necessidade de ser aceito, amado, surge em todas as falas dos jovens, seja de forma explícita, consciente, ou não. Na verdade, é a falta de amor e a busca do outro que perpassam todos os depoimentos. $\mathrm{O}$ viver de forma inautêntica, sem sentido, tem em suas bases a condição co-originária do ser-com, uma vez que o ser é co-originário ao mundo, ou seja, é sendo-no-mundo. Por isso será impossível para o Dasein passar de um modo de ser impróprio para uma existência com propriedade plena, uma vez que essa condição de existir de maneira co-originária ao mundo e com os outros entes e Daseins, não permite que tal aconteça.
A experiência revelada nas narrativas expressa as pessoas que eles são no momento, vivenciando sentimentos de não serem aceitos e reconhecidos como pessoas de valor, ou seja, sem reconhecimento existencial. Nas narrativas de alguns desses jovens, percebe- se a necessidade de serem aceitos e amados tal como se percebem; e o sofrimento por não estarem inteiros na sua relação com os pais, ou seja, com o outro. Assim, viver nessas condições será sempre um vivenciar de angústias e sofrimentos constantes, em razão da consciência de não existir, nem para si e nem para o outro. O sentimento de não ser-com-os-outros do seu mundo gera situações que conduzem à sensação de fracasso, desesperança e solidão, criando uma possibilidade para o fim do sofrimento, de maneira mortal, como se viu nas experiências desses jovens, através do suicídio.

A solidão é muito presente nas narrativas apresentadas. Muitas das adolescentes dizem da sua falta de amigas, de não ter com quem trocar as suas experiências de inquietudes e tristezas. As relações interpessoais são caracterizadas, em sua maioria, pelos conflitos e disputas de homens, territórios e poder. Há uma carência de vínculos afetivos que possam servir de continente às angústias por que elas passam, seja no contexto familiar ou social. Pode ser em razão dessa falta que alguns deles recorrem às drogas, à vida sexual promíscua e mesmo aos conflitos com os seus pares na rua e escolas. Os comportamentos hostis, assim como as respostas agressivas, muitas vezes em direção aos familiares, podem ser interpretados como expressão do sofrimento por não ser amado.

As experiências narradas nos fazem ver que viver na impropriedade nos afasta do sentido que podemos dar à própria vida e de uma existência com mais propriedade. Elizabete revela que não consegue contatar com a experiência do seu ser. Confunde a experiência autêntica de ser com uma imagem que idealiza de si mesma, uma vez que é esta a esperada pelos outros e a quem ela satisfaz, para, assim, sentir-se amada. Em outras palavras, podemos dizer que Elizabete, como outras jovens aqui apresentadas, deixou-se absorver pela cotidianidade, passando a viver na impropriedade e na impessoalidade, como nos faz pensar Heidegger (1927/1981).

Essa condição, portanto, vai gerar uma alienação de si; um não-sei-quem-sou, que, além de permear de forma contundente e previsível o processo de adolescer, agravase pelo sofrimento gerado pelas circunstâncias desfavoráveis com que cada um deles se depara em sua vida e pela própria condição de existir.

Pensando o suicídio, quem sabe este pode ser compreendido como uma maneira de lidar com a angústia, eliminando-a. Seria a incapacidade de enxergar uma existência na qual o outro se institua de um jeito novo, distinto daquele que o absorveu. Ou seja, a descrença de que a vida possa ser vivida de outra maneira, com um sentido próprio, o que significaria uma recusa em continuar sendo como antes. O suicídio ainda poderia ser pensado como 
uma forma desesperada de se apropriar da vida, do seu ser, ainda que seja eliminando-o, o que não deixa de ser um modo de assumir o seu destino, como um ser-para-amorte. É possível pensar o suicídio em razão, entre tantos outros motivos, do desespero de não poder enfrentar a finitude da existência, o ser-para-a-morte. Assim, esse ato pode significar a onipotência de se tomar nas mãos o destino do ser-para-morte. Isso pode ser percebido nas experiências dos jovens deste estudo, que colocam a tentativa de morte como um desejo de sair do sofrimento, sem que se pense na possibilidade de retomar a vida com um modo de ser diferente. Ao pensar dessa maneira, o desejo de morte então se sobrepõe, pela descrença em novas possibilidades existenciais. Pois a resposta continua sendo o outro, o que significa um não apropriar-se da existência, como se percebe nas palavras de Márcia:

Eu sou muito nova... eu tenho quinze anos agora... eu ainda vou aproveitar muito.... Que um dia vai chegar uma pessoa que me faça feliz... Eu estou esperando isso.... E também não estou fazendo nada para ser feliz...

Mesmo após a tentativa de morte, ou seja, a crise, Márcia ainda não conseguiu perceber outra possibilidade para a sua existência. Continua sem apropriar-se do seu ser, à espera de alguém que faça isso por ela. $\mathrm{Na}$ verdade, compreendo que esta é uma tarefa muito árdua para essa menina de quinze anos, que desde os treze foi expulsa de casa pelo pai, que a rejeita até hoje. Foi obrigada a entrar na adolescência como uma adulta capaz de autonomia, em todos os sentidos, mas sem condições reais para fazê-lo, em razão da natural imaturidade da idade e da sua condição de ser-no-mundo.

Outra direção do olhar nos levaria a entender o suicídio como uma paralisação diante da abertura do ser-aí às possibilidades e, diante da finitude, a morte, que não se sabe quando virá e, assim, tenta-se antecipá-la. Desse modo, alivia-se a angústia de saber-se um ser que, em sendo um ser-para-a-morte, deve acolher, em seu projeto, essa possibilidade. Viver um projeto que inclua o serpara-a-morte não significa antecipá-la, eliminá-la ou viver no sofrimento, morrendo a cada momento. É, antes de tudo, encará-la como uma das possibilidades do ser-aí, como abertura ao mundo. É viver a angústia como uma das possibilidades do ser, entre elas, a morte. Ainda sobre a morte e seguindo as idéias de Heidegger, Novaes de Sá (2010, p. 189) afirma:

O Dasein se esquece de que existe, projetando-se e compreendendo-se antecipadamente em suas possibilidades, e se perde nos ruídos ambíguos do falatório. Nesse contexto, a morte é encarada como um fenômeno do qual é preciso desviar-se, pois a existência deseja fugir da angústia perante a possibilidade do não-ser. É somente experienciando essa angústia diante do nada que o Dasein pode escolher-se a si mesmo e encontrar o que tem de mais próprio e singular para além das estruturas do "mundo público" e impessoal.

Assim, sair da vida pode ser entendido como uma recusa a enfrentar a responsabilidade por ela. Seria antecipar o final do ser, que é a morte. Como diz Boss (xxxx/1981, p. 40), “(...) o futuro do ser humano, ele só o alcança completamente no momento da morte”. Ao mesmo tempo, seguindo o pensamento de Boss, a culpa, tal como a angústia, por ser inerente ao homem, dela jamais este se livrará. De nada adiantam as explicações concretas, no nível biológico, psicológico ou psicodinâmico sobre a culpa e a angústia, já que esta se constitui pela falta, que sempre acompanhará o homem. Vista sob o ângulo também da culpa, do ficar-a-dever, no dizer de Boss, o suicídio se configuraria no ficar-devendo, ou no débito, segundo Heidegger, no abrir mão do poder-ser; no desvencilharse da existência escolhida e responsável e mergulhar no vácuo do não-ser. Seria uma entrega a esse sentimento indissociável do ser humano, que é a culpa.

A visão de Dasein, de ser-aí, ser-para-a-morte e cotidianidade, entre outras idéias heideggerianas, nos faz encontrar neste filósofo um pensamento extremamente contemporâneo, criando um horizonte que favorece uma compreensão mais ampla das questões da existência, entre elas, o suicídio. Assim, o que fica mais evidente e que ressalta aos nossos olhos nessa visada fenomenológica sobre o suicídio, é a dimensão existencial que se revela em cada experiência narrada. Independente das condições que circunscrevem o suicídio e por meio das quais esse fenômeno é abordado, tais como as condições materiais, sociais, psicológicas e psiquiátricas, entre outras, o que vem em primeiro plano e que se impõe aos nossos olhos diante de todas as categorizações do ser humano, é a existência. É a capacidade do homem para existir de uma forma singular, numa condição existencial criadora de sentidos, fazendo com que pessoas em condições de vida semelhantes não percorram o caminho previamente determinado e esperado por uma sociedade tecnicista e que ignora o outro enquanto sujeito singular.

O que sugere que antes de qualquer categorização, rótulo ou algo semelhante que tente aprisionar o homem, está o ser, que surge na clareira do ser-aí, na abertura do homem ao mundo. Pois é através de um movimento de velamento e desvelamento que a existência se constrói, num eterno e infindável processo de vir-a-ser, impedindo que o Dasein seja considerado um ser simplesmente dado ou cristalizado no seu desocultamento, condição intrínseca da existência. É também essa condição que nos legitima como responsáveis pelo nosso destino e, ao mesmo tempo, nos lança na incerteza desse mesmo destino, quando nos coloca como seres de possibilidades e assim, existindo num processo permanente de escolhas, em busca da completude que nunca virá. Portanto, diferentemente da 
tradição objetivista e técnica que prevalece nas ciências e no mundo ocidental, pensar o suicídio numa perspectiva fenomenológica hermenêutica heideggeriana desvela a possibilidade de se considerar este fenômeno como expressão da angústia e do desamparo humano diante de um mundo que será sempre inóspito para o Dasein na sua condição existencial de ser-no-mundo. E esta, certamente, se constitui num outra possibilidade de pensar o suicídio; não a única ou a mais verdadeira, apenas outra possibilidade, mais condizente com a condição de singularidade e de solicitude que caracterizam o ser humano.

\section{Referências}

Bauman, Z. (2007). Tempos Líquidos. Rio de Janeiro: Zahar.

Boss, M. (1981). Angústia, Culpa e Libertação: ensaios de psicanálise existencial. São Paulo: Duas Cidades (Original publicado em 1971).

Camus, A. (1952). Le mythe de Sisyphe. Paris: Gallimard.

Dantas, J. B. (2009). Tecnificação da vida: uma discussão sobre o discurso da medicalização da sociedade. Fractal: Revista de Psicologia, 21 (3), 563-580.

Dutra, E. (2002). Comportamentos autodestrutivos em crianças e adolescentes. Em C. S. Hutz (Org.). Situações de risco e vulnerabilidade na infância e adolescência (pp. 52-82). São Paulo: Casa do Psicólogo.

Dutra, E. (2004). Considerações sobre as significações da psicologia clínica na contemporaneidade. Estudos de Psicologia (Natal), 9 (2), 381-388.

Dutra, E. (2010). Suicídio no Brasil: estratégias de prevenção e intervenções. In Hutz, C. S. (Org.). Avanços em Psicologia Comunitária e intervenções psicossociais. S.P.: Casa do Psicólogo, (pp. 223-264).
Dutra. E. (2000). Compreensão de tentativas de suicídio de jovens sob o enfoque da Abordagem Centrada na Pessoa. Tese de Doutorado. Instituto de Psicologia. Universidade de São Paulo (USP).

Figueiredo, L. C. (1996). Revisitando as Psicologias: Da epistemologia à ética das práticas e discursos psicológicos. São Paulo: EDUC / Petrópolis: Vozes.

Heidegger, M. (1981). Todos nós... ninguém. Um enfoque fenomenológico do social. Trad.: Dulce Critelli. São Paulo: Moraes (Original publicado em 1927).

Heidegger, M. (1999). Ser e Tempo. 8ª ed. Petrópolis: Vozes (Original publicado em 1927).

Novaes de Sá, R. (2010). A analítica fenomenológica da existência e a psicoterapia. Em Ana Maria Lopez Calvo de Feijoo (Org.). Tédio e Finitude: da Filosofia à Psicologia [pp. 177199]. Belo Horizonte: Fundação Guimarães Rosa.

Procópio, D. (1999). A crise como possibilidade do encontro do indivíduo consigo mesmo: Uma leitura heideggeriana. Dissertação de Mestrado. São Bernardo do Campo. Universidade Metodista de São Paulo.

Safra, G. (2004). A po-ética na clínica contemporânea. Aparecida: Idéias \& Letras.

Elza Dutra - Psicóloga e psicoterapeuta. Doutora em Psicologia Clínica pela Universidade de São Paulo (USP), e Docente do Programa de Pós-Graduação em Psicologia da Universidade Federal do Rio Grande do Norte (UFRN). Endereço Institucional: Universidade Federal do Rio Grande do Norte, Centro de Ciências Humanas Letras e Artes, Departamento de Psicologia. Campus Universitário, Lagoa Nova, s/n. CEP 59075-970. Natal/RN. E-mail: elzadutra.rn@gmail.com

Recebido em 06.07.11 Aceito em 15.11.11 